\title{
Evaluation of the effect of the magnetic apparatus on the water, the plant and the state of the soil
}

\author{
Anis Elaoud ${ }^{1}$, Ben Salah Nahla ${ }^{1,2}$, Rim Jalel $^{3}$ and Nejib Turki ${ }^{4}$ \\ ${ }^{1}$ University of Carthage, Laboratory of Environmental Sciences and Technologies, Higher Institute of Sciences and Technology of Environment, \\ Tunisia \\ 2University of Sfax, Laboratory of Probability and statistics, Faculty of Sciences of Sfax, Tunisia \\ ${ }^{3}$ University of Sousse, Higher institute of Agriculture Chott Mariem, Tunisia \\ ${ }^{4}$ University of Carthage, National Institute of Agronomy Tunis, Tunisia
}

Received 05 Jan 2019, Accepted 02 June 2019, Available online 30 June 2019, Vol.x (June/Jul 2019 issue)

\begin{abstract}
Magnetic devices are nowadays used in different fields. Primarily, these devices have an effect on the environment: water, plant and soil. The experimental tests carried out showed a significance of the treatment of water by the magnetization technique. The effect of the magnetic device is illustrated by the increase of cucumber and melon yield respectively 25\% and 27\%; Thus, an improvement in the state of the soil is recorded by reducing its compaction.
\end{abstract}

Keywords: Magnetic, state of soil, yield, Resistance of penetration, water.

\section{Introduction}

The impact of climate change, increased prevalence of drought and population growth are the main factors limiting agricultural production. To prevent food security in arid and semi-arid zones from being subjected to the vagaries of the climate, optimal water and soil management are essential. To address this problem, research therefore focuses on innovation that can improve efficiency, promote equity and protect the environment.

A new technology, based on a physical treatment of water by a magnetic field, can constitute a solution of recourse allowing the valorization of the soil and water resources and to improve the production of the crop since a good supply of water and fertilizers are provided.

The aim of this study is to evaluate and fully understand the effects of the newly introduced magnetism technology in Tunisia on the physical parameters of the soil on the one hand and on plant parameters on the other hand (Ben Amor et al., 2016).

Thus, researchers have shown that the magnetic apparatus changes the quality of water and increases crop yield (Ben Amor et al., 2018; Cheikh et al., 2018; Elaoud ets al., 2016).

Water magnetic, as called by some, is a water that has passed through a magnetic field. Magnetic devices for magnetic water treatment or water softener are respectful to the environment, cost competitive and no

*Correspoding author's ORCID ID: 0000-0000-0000-0000 DOI: https://doi.org/10.14741/ijcet/v.9.4.7 energy needs (Hozyan and Qados 2010). In the literature (Alimi et al., 2006), wall treatment is the most developed. However, little research are oriented towards the improvement of the characteristics of the magnetic machine and the optimization of the parameters for a treatment against the salinity of irrigation water.

Thus, the magnetized water used for irrigation can improve the productivity of water (Maheshwari and Grewal, 2009), thus retaining the water supply for the future in the light of the world expected water shortage.

In this context, our topic arises in order to study the characteristics related to the magnetic machine and the variation of water characteristics, plant yield and soil state.

\section{Materials and methods}

\subsection{Site of experiences and process}

The study plot is located in Nabeul-Tunisia with a clay sand soil (21\% clay, 6.9 loam and $72.1 \%$ sand).

The plot is split into two parts, one considered as irrigated control with irrigation water and the other irrigated with magnetized irrigation water where the magnetizer is placed directly on the main pipe.

The salinity of irrigation water used in this experiment was about $2.5 \mathrm{~g} / \mathrm{l}$. The experiment was carried out in complete random block device with three repetitions. In each block, 100 plants were distributed randomly with 2.2 per $\mathrm{m}^{2}$ planting density. In this work, a part is treated (magnetized water) and a part control light (raw water). 


\section{Culture}

The yields of cucumber and melon were studied.

\subsection{Apparatus and experimental device}

\section{Magnetic device}

The device used is brand Delta Water with a magnetic field strength of 3400 Gauss (fig. 1).

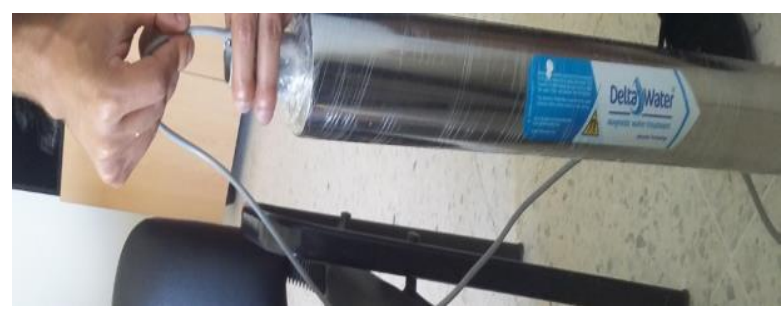

Fig.1 Magnetic device

\subsection{Soil characterization parameters}

\section{Resistance to penetration}

Resistance to penetration is a physical parameter that allows knowing the state of a soil. It is measured in situ using a penetrometer (Fig. 2) whose handling is the depression into the ground of the device that records every centimeter runs a force value.
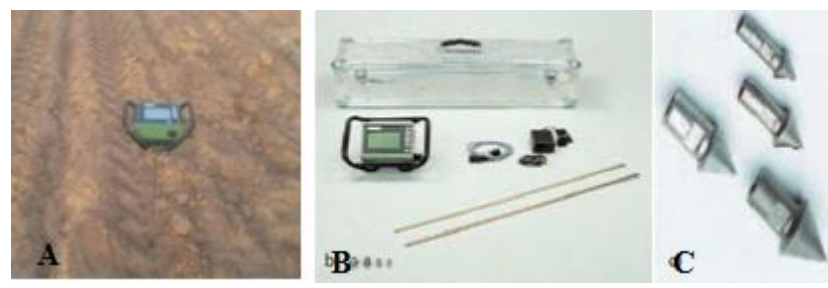

Fig.2 Penetrometer

\section{Results and discussion}

\subsection{Evaluation of yield and plant height.}

These tests demonstrated the favorable effect on soil physical parameters such as a decrease in resistance to soil penetration at the irrigated plot with magnetized water and growth and the yield in terms of quantity. The results indicated an acceleration of the growth rate during the early stages. They also showed a relevant development of leaf potential. This method is designed to increase the yield cucumber and melon respectively $25 \%$ and $27 \%$.

This is consistent with the results of (Taimourya et al, 2015; Elaoud et al., 2016; Ben Amor et al., 2018) which showed that irrigation with magnetized water resulted in an increase of the yield respectively of Cabbage, Melon and Potato.
The height of the plant reached $48 \mathrm{~cm}$ (Fig. 3) for the sample irrigated with magnetized water while it was recorded that $40 \mathrm{~cm}$ for the sample irrigated with untreated water. The height of the plant reached $49 \mathrm{~cm}$ (Fig. 3) for the sample irrigated with magnetized water in the disc, and only $42 \mathrm{~cm}$ was recorded for the sample irrigated with untreated water.

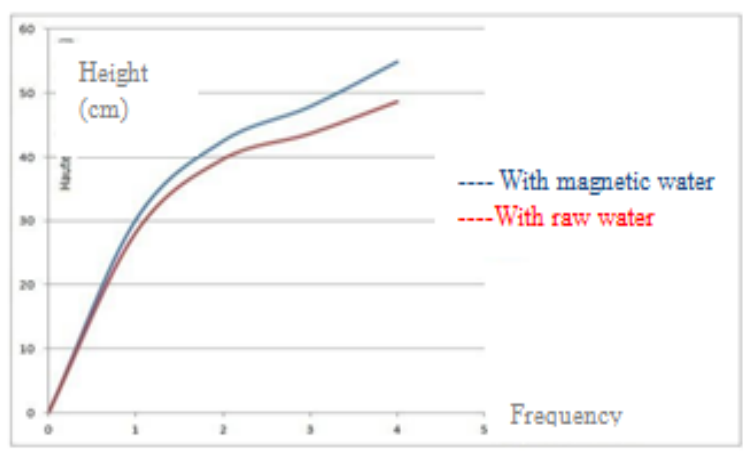

Fig.3 Measuring the height of the plant

\subsection{Soil state}

In this part, we study the state of irrigated soil with raw water and other irrigated with magnetized water. The measure of the resistance to the penetration of the soil is the indicator of its state.

At the $10 \mathrm{~cm}$ horizon, the penetration resistance at the level of the irrigated plot with untreated water is $1.5 \mathrm{~N} / \mathrm{cm}^{2}$, whereas the resistance measured at the level of the irrigated plot with magnetized water $1 \mathrm{~N} / \mathrm{cm}^{2}$ (Fig.4).

Irrigation with magnetized water improves the state of the soil by reducing its compaction.

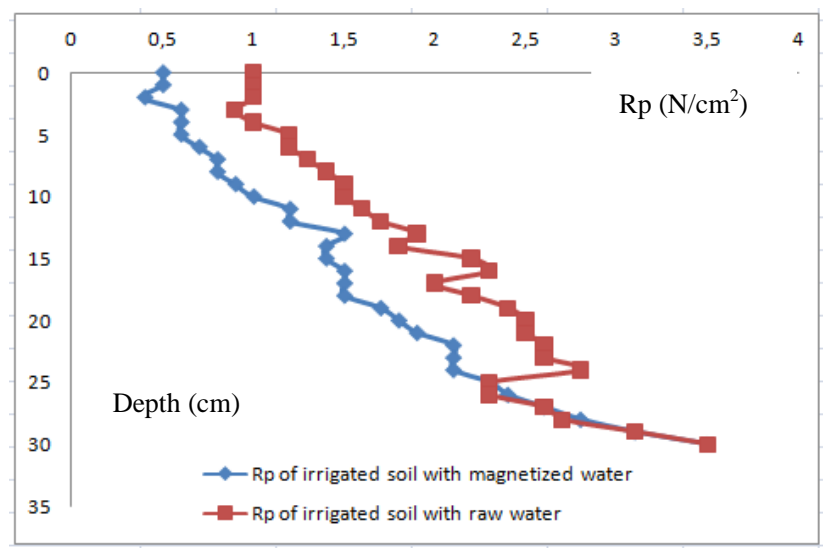

Fig.4 Measure of soil resistance to penetration function of number pas tractor and working conditions

\subsection{Statistical analysis}

If the calculated $\mathrm{F}$ value is greater than the $\mathrm{F}$ critical value, there is a real relation between dependent and independent variables. The significance test of regression analysis (F-test) is performed according to the standard procedure. 
This test follows an F-distribution with degree of freedom (d.o.f) $v 1=3$ and $v 2=56$ for magnetized water. Also, the experience are significant were $\mathrm{F}$ calculated $(\mathrm{F}=695.485276)>$ critical value $\mathrm{F}(2.8379 \mathrm{E}-4)$.

\section{Conclusions}

The physical treatment of water by a static magnetic field improves the structural condition of the soil and the plant growth with a significant gain in production and yield. This affordable technology paves the way for specific treatments using the magnetic properties of water, which requires further investigations. The direct effects of magnetic technology on both soil and plant variants should also be better understood using statistical analysis through which correlations between the different parameters could be observed.

\section{Acknowledgment}

This study is carried out by the 'Delta Water' device. Our thanks to the company and to Mr. Ahmed and Cherif Ibrahim (Egypt).

\section{References}

Alimi F., Tlili M., Amor M., Gabrielli C. and Maurin G. (2006). Influence of Magnetic Field on Calcium Carbonate Precipitation.Desalination 206: 163- 168.
Ben Amor H., A. Elaoud, N. and K. Elmoueddeb Influence of Magnetic Field on Water Characteristics and Potato Cultivation, Journal of Environmental and Agricultural Sciences. 16, 32-41

Ben Amor H., Anis Elaoud, N. Ben Salah and K. Elmoueddeb (2017), Effect of Magnetic Treatment on Surface Tension and Water Evaporation. International Journal of Advance Industrial Engineering. ISSN: 2320-5539, p119-124. Doi.Org/10.14741/Ijae/5.3.4.0.

Cheikh O., A. Elaoud, H. Ben Amor et M. Hozayn (2018), Effect of permanent magnetic field on the properties of static water and germination of cucumber seeds. International Journal of Multidisciplinary and Current Research. pp108-1

Elaoud A., N. Turki, H. Ben Amor, R. Jalel and N. Ben Salah (2016), Influence of the Magnetic Device on Water Quality and Production of Melon. International Journal of Current Engineering and Technology, E-ISSN 2277- 4106, vol.6 n.6. Dx.Doi.Org/10.14741/Ijcet/22774106/6.6.2016.47

Hozayn M. and Qados A. (2010). Irrigation With Magnetized

Water Enhances Growth, Chemical Constituent and Yield of

Chickpea (Cicerarietinum L.). Agriculture and Biology Journal of North America 1(4): 671-676.

Maheshwari L. and Grewal H.S. (2009). Magnetic treatment of irrigation water: Its effects on vegetable crop yield and water productivity. Agricultural Water Management 96 : 1229-1236.

Taimourya H., Bourarach E.H., El Harif A., Hassanain N., Masmoudi L., Baamal L., and Oussible M. (2015).Évaluation de la productivité du chou pommé (Brassicaoleracea), sous l'effet de l'irrigation avec une eau traitée magnétiquement, dans la région de Casablanca (Maroc). Rev. Mar. Sci. Agron. Vét. 3 (2):27-36. 